The International Journal Of Engineering And Science (IJES)

|| Volume || 6 || Issue || 3 || Pages || PP 57-65|| 2017 ||

ISSN (e): $2319-1813 \operatorname{ISSN}(\mathrm{p}): 2319-1805$

\title{
Bituminous Pavement Recycling - Effective Utilization of Depleting Non-Renewable Resources
}

\author{
Deepak Baskandi \\ Email:baskideepak@gmail.com
}

\begin{abstract}
-
Bituminous pavement recycling is an effective and worldwide proven technique of conserving Energy, Environment and Economy while ensuring maintenance and preservation of roadway network. In the pavement recycling process, the materials from deteriorated pavements known as Reclaimed Asphalt Pavement (RAP), is partially or fully reused in fresh construction. The concept of RAP lies in restoring the physico-chemical properties of the aged bitumen to its original and at the same time to enhance the mechanical properties and strength of the aged binder. This paper gives a brief overview of various recycling methods of bituminous pavement including (1) Hot mix recycling, (3) Hot-in-place recycling, (3) Cold central plant recycling, (4) Coldin-place recycling, and (5) Full depth reclamation, their advantages, selection considerations, review of mix design procedure, unresolved issues related to their use and future scope in Indian context.
\end{abstract}

Keywords: Cold in-place recycling, Cold mix recycling, Full depth reclamation, Hot in-place recycling, Hot recycling, $R A P$.

Date of Submission: 28 February $2017 \quad$ Date of Accepted: 11 March 2017

\section{INTRODUCTION}

Rapid economic development and population growth have resulted in an extensive network of roads and the demand for developing new and better road network has increased manifold in the last 15 to 20 years. As the traffic volumes and gross vehicle weight have increased, so is the requirement for widening/improvement of existing roadways. Further, due to rapidly expanding road network and since majority of earlier constructed roads are near/at/or past the end of their intended design life, increased emphasis has been placed on preventive maintenance and preservation of existing roadways. Funds available for preventive maintenance, pavement improvement/rehabilitation/reconstruction have not been able to keep pace with the growing requirements which has resulted in significant reduction in the overall road condition and the level of service provided by the roadway within the network.

A world bank study has indicated that each $\$ 1.00$ expended at the first 40 percent drop in roadway quality will result in a saving of $\$ 3.00$ to $\$ 4.00$ compared to the expenditure which would be required at the 80 percent drop in quality. As overall budgetary funds are always limited, innovation is required in order to do more preventive maintenance, rehabilitation, reconstruction of roads at a lesser cost. Pavement recycling is one such effective and well established proven technology for increasing the effectiveness of being able to do more at lesser cost. It is a logical and practical solution to conserve our diminishing supply of construction materials and to help reduce the ever increasing cost of preserving of existing pavement network.

Pavement recycling is not a new concept and recycling of bituminous pavements is a standard practice in many countries of the world since last 35 years. The various ecological and economic advantages which contributed to rapid enhancement of recycling processes throughout the world are:

- Conservation of aggregates and binder.

- Preservation of the environment and conservation of natural resources.

- Preservation of existing pavement geometrics and clearances.

- Conservation of energy and labour.

- Less user delay during construction.

- Reduction in reflection cracking.

- Substantial saving in terms of cost.

2.1Broad Classification

\section{RECYCLING METHODS AND TECHNIQUES}

Based on the process adopted for recycling the bituminous mix, it can be broadly classified as central plant recycling and in-situ recycling. If RAP is transported and modified in a central plant, away from construction site then the process is known as central plant recycling. In-situ recycling process involves in place modification 
and utilisation of the RAP. Further, if heat is applied to modify RAP, then the process is known as hot mix recycling whereas, in case of cold mix recycling, RAP is modified using recycling agent (like, low viscosity emulsion, small amount of cement or lime) without application of heat. The classification is schematically summarized in Fig. 1.

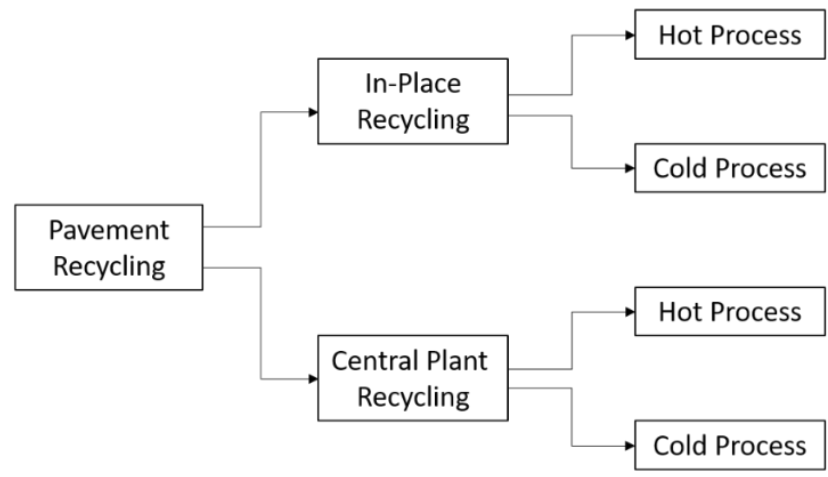

Figure 1. Classification of Bituminous Recycling Methods Based on Processes

Based on the depth of old pavement removed and re-laid recycling methods could be classified as surface recycling and full depth reclamation [1]. Surface recycling involves scarification and relaying of only the top layer however, if the base failure occurs then the pavement layers up to base layer is removed and constructed again. This process is known as full depth reclamation. PIRAC[2] maintains that the types of recycling can be classified according to:-

- The type where mixing is carried out (in-situ or in-plant)

- The characteristic of the material to be recycled.

- The binder type selected for recycling (cement, bitumen, bitumen emulsion or bitumen)

ARRA [3] on the other hand categorized recycling as Cold Planning (CP), Hot Recycling (HR), Hot In Place Recycling (HIR) which is further classified to include Surface Recycling, Remixing and Repaving, Cold Recycling (CR) further sub-categorized into Cold In Place Recycling (CIR) and Cold Central Plant Recycling (CCPR) and Full Depth Reclamation (FDR) which has further been classified as Pulverization, Mechanical stabilization, Bituminous stabilization and Chemical stabilization. Karlsson and Isacsson[4] have schematically presented the bituminous recycling classification as in Fig. 2.

Thus, recycling operations include Hot Mix Recycling, Hot In-place Recycling (HIR), Cold Central Plant Recycling, Cold In-place Recycling (CIR), and Full Depth Reclamation (FDR). Among this, hot mix recycling is very commonly used for producing hot mix asphalt, which can be used as overlays in preventive maintenance operations where as thick layers in rehabilitation. Hot in- place and Cold in-place recycling are commonly used for preventive maintenance operations, whereas full depth reclamation is generally used for rehabilitation work. The choice of a particular technique depends on engineering considerations (such as pavement distress and structural strength), availability of necessary equipment, availability of experienced contractor, initial cost, construction impact on traffic, and long term maintenance costs. Different recycling methods are as follows.

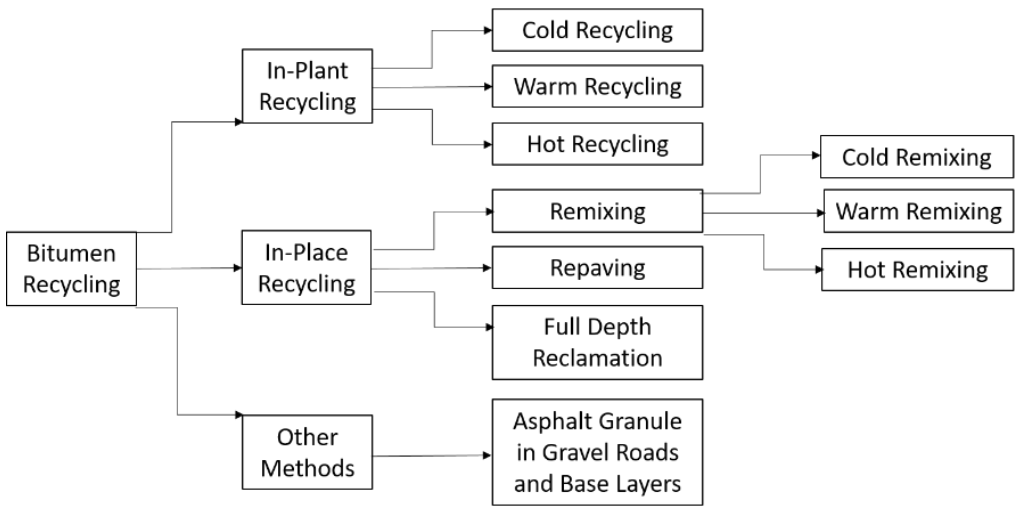

Figure 2. Methods of Bitumen Pavement Recycling 


\subsection{Hot Mix Recycling}

Hot mix recycling is a method in which the RAP is combined with new aggregate and an asphalt cement or recycling agent to produce hot mix asphalt (HMA). Both batch and drum type hot mix plants are used to produce recycled mix. The RAP is obtained from pavement milling with a rotary drum cold planing machine and may be further processed by ripping and crushing operations, if needed. The mix laydown and compaction equipment and procedures are same as for conventional HMA. The ratio of RAP to new aggregates depends on the mix design, on the type of hot mix asphalt plants, and on the quality of stack emission generated. Typical RAP to aggregate proportions vary between 10:90 to 30:70, although a maximum of 50:50 have been reported for drum mix plants [5]. The use of microwave technology has allowed the use of a higher amount of RAP, because the RAP can be preheated. The advantages of hot mix recycling are as follows.

- Significant structural improvements can be obtained with little or no change in thickness by improving the existing materials.

- Additional right-of-way is not needed.

- Surface and base distortion problems can be corrected

- Performance of recycled mix is as good as conventional HMA mix.

- Disposal problem inherent in conventional methods are eliminated.

- Conservation of non-renewable resources.

- Economic savings are achieved.

\subsection{Hot In-Place Recycling}

It is a method which is performed on site with the RAP material obtained from the existing pavement. The deteriorated asphalt pavement is heated and softened to allow it to be scarified or mixed to a specified depth. If required, new hot mix material and/or recycling agent is added to the RAP material thoroughly mixed and further placed and compacted with regular HMA paving equipment. In this method, the existing pavement is typically processed to a depth of $20 \mathrm{~mm}$ to $40 \mathrm{~mm}$. The process can be carried out as a single-pass or as a multiple-pass operation. In the single-pass operation, the scarified existing pavement material is combined with new material, if needed, and compacted. In a multiple-pass operation, the scarified material is re-compacted and then the new wearing surface is applied. The advantages offered by this method include the following:

- Surface irregularities and cracks are filled.

- Aggregate which has lost the asphalt binder coating through stripping, is remixed and recoated.

- Ruts and holes are filled, shoves and bumps are levelled, drainage and crowns are reestablished.

- Flexibility is restored by chemically rejuvenating the aged and brittle pavement.

- Aggregate gradation and asphalt content may be modified by some variations of this process.

- Enhances highway safety through increased frictional resistance.

- Reduces interruptions in traffic flow when compared to other conventional rehabilitation techniques.

- Hauling costs can be minimized.

- Aggregate and asphalt binders are conserved.

\subsection{Cold Central Plant Recycling}

In this method, the bitumen recycling takes place in a central location using a stationary cold mix plant. The RAP used is obtained by cold planning or by ripping, scarifying and crushing operations and is subsequently stockpiled at the plant location. This plant usually has a number of cold feed bins for the RAP material and new aggregate, a well-controlled liquid recycling additive system, a pugmill, a hopper for temporary storage and conveyor belt. This process is similar to the hot central plant mixing except, no heating is involved and therefore low viscosity emulsion is used as binder in most of the cases. Cold central plant recycling is used in projects that require high rates of production or close control of the mix design[6].

In this method, existing pavement materials are used along with recycling agent. The depth of treatment is typically from 75-100 mm. Although, in some cases, virgin aggregate may be added to the recycled material to change or improve the RAP characteristics, normally this procedure is carried out without transportation of any material except the recycling agent. The technique consists of pulverization of the existing pavement, sizing of the RAP, addition of recycling agent and the placement and compaction of the recycled mix. The newly developed recycling trains consist of large cold milling machine with a screening and crushing unit, and a mixing device attached to it. Conventional HMA is laydown and compaction equipment are used to pick up the processed material from windrow, and subsequent placement and compaction. The advantages of cold in-place recycling include the following[7]:

- Significant pavement structural improvements may be achieved without changes in horizontal and vertical geometry and without shoulder reconstruction. 
- All types and degrees of pavement distress can be treated.

- Reflection cracking normally is eliminated if the depth of pulverization and reprocessing is adequate.

- Pavement ride quality is improved.

- Old pavement profile, crown, and cross slope may be improved.

- Production rate is high.

- Only thin HMA overlay or chip seal surfacing is required on most projects.

- Engineering costs are low.

- Conservation of non-renewable resources.

- Energy is conserved.

- Air quality problems resulting from dust, fumes, and smoke are minimized.

- Frost susceptibility may be reduced.

- Pavement widening operations may be accommodated.

\subsection{Full Depth Reclamation}

It is a recycling technique in which all of the HMA layer and a predetermined amount of underlying materials are treated to produce a stabilized base course. According to ARRA[3], Full Depth Reclamation (FDR) is defined as " A pavement rehabilitation technique in which the full flexible pavement section and a predetermined portion of the underlying materials are uniformly crushed, pulverized or blended, resulting in $\mathrm{s}$ stabilized base course."

It is basically a cold mix recycling method in which different types of additives including asphalt emulsion and chemical agents such as calcium chloride, Portland cement, fly ash, and lime are used for improving the quality of the base. In some cases, new material is added to obtain a required depth of the improved base. The five main steps in this process are pulverization, introduction of additive, shaping of the mixed material, compaction, and application of a surface or a wearing course. Full depth reclamation has been recommended for pavements with deep rutting, load-associated cracks, nonload associated thermal cracks, reflection cracks, and pavements with maintenance patches such as spray, skin, pothole, and deep hot mix. It is particularly recommended for pavements having a base or subgrade problem. The advantages offered by full depth reclamation include the following:

- Significant improvement in pavement structure without changing its geometry and shoulder reconstruction.

- Restores old pavement to the desired profile, eliminate existing wheel ruts, restores crown and slope, and eliminate potholes, irregularities, and rough areas.

- Recycles existing materials saving natural resources and energy.

- Process is accomplished in-place.

- Heating, mixing, and hauling costs of conventional maintenance techniques can be eliminated.

- Roadway cross section can be maintained or adjusted; grade can be lowered in curbed sections to regain curbs or reshaped in poor draining sections to improve drainage.

- It can eliminate alligator, transverse, longitudinal, and reflection cracking. Ride quality can be improved.

- Eliminate material disposal concerns.

- Frost susceptibility may be improved.

- Savings realized by reducing total pavement thickness.

\section{CONSIDERATIONS FOR SELECTING DIFFERENT RECYCLING TECHNIQUES}

The choice of rehabilitation technique is broadly based on the engineering considerations, economic considerations and energy considerations. The rehabilitation alternatives are decided based on the observed pavement distress, laboratory and field evaluation of existing material and design information[8].The choice of a particular recycling technique method should be primarily on the basis of the type of distress shown by the existing pavement. This is because all of the recycling methods are not equally suited for treating different types of distress, and hence the choice must be made for the particular method which is capable of rectifying the existing distress conditions. The applicability of a particular recycling technique not only depends on the pavement defect, but also on the extent and severity of the distress. Therefore, a comprehensive evaluation of the existing pavement and its condition is necessary before selecting any recycling technique. A detailed study of applicability for the use of different recycling techniques and considerations is presented in Table1 $[9,10]$.

Table 1.Applicability and considerations for different recycling procedures

\begin{tabular}{|c|l|l|}
\hline Process & \multicolumn{1}{|c|}{ Applicability } & \multicolumn{1}{|c|}{ Considerations } \\
\hline Hot Mix Recycling & $\begin{array}{l}\text { Can be used to treat surface defects, deformation, } \\
\text { load and non-load associated cracks, and } \\
\text { maintenance patching. Material obtained from an } \\
\text { existing pavement can be stockpiled for future use. }\end{array}$ & $\begin{array}{l}\text { Percentage of RAP that can be varied } \\
\text { depending on recycling mix properties } \\
\text { and the type of hot mix plant. RAP/virgin } \\
\text { material blend is typically 10:90 to 30:70, }\end{array}$ \\
\hline
\end{tabular}




\begin{tabular}{|c|c|c|}
\hline & $\begin{array}{l}\text { Also, stockpiled RAP material can be carefully } \\
\text { blended in a plant with other materials to achieve } \\
\text { proper mix. }\end{array}$ & with a maximum of 50:50 (drum plant). \\
\hline Hot In-Place Recycling & $\begin{array}{l}\text { Can be used to treat surface defects, corrugation and } \\
\text { surface rutting and longitudinal and slippage } \\
\text { cracking up to } 50 \mathrm{~mm} \text { depth. The existing pavement } \\
\text { material can be used fully, resulting in a minimal } \\
\text { demand for virgin materials. This method is } \\
\text { particularly suitable for busy highways or streets } \\
\text { which cannot be kept closed for a long time. }\end{array}$ & $\begin{array}{l}\text { Hot in-place recycling can involve } \\
\text { significant amounts of heavy machinery } \\
\text { and equipment. Because of high } \\
\text { mobilization costs, there should be } \\
\text { enough work in a particular area to make } \\
\text { this process cost effective. Also, since this } \\
\text { method frequently involves long } \\
\text { equipment trains, it may not be suitable } \\
\text { for local residential streets with very } \\
\text { limited space for maneuvering of } \\
\text { equipment. }\end{array}$ \\
\hline $\begin{array}{l}\text { Cold Central Plant } \\
\text { Recycling }\end{array}$ & $\begin{array}{l}\text { All types of cracks except those caused by fatigue } \\
\text { and base failure. }\end{array}$ & $\begin{array}{l}\text { May require aeration before compaction } \\
\text { to reduce moisture. Wearing surface is } \\
\text { normally required. }\end{array}$ \\
\hline $\begin{array}{ll}\text { Cold } & \text { In-Place } \\
\text { Recycling } & \end{array}$ & $\begin{array}{l}\text { Can be used to treat rutting in asphalt layers below } \\
\text { the surface; load associated block and thermal } \\
\text { cracks; and maintenance patching. The existing } \\
\text { pavement material can be used fully leading to } \\
\text { substantial savingsby avoiding transportation of } \\
\text { new materials. Also, since no heat is used in this } \\
\text { technique, there are no air quality concerns } \\
\text { associated with it, and savings are also realized in } \\
\text { energy and money. This method can improve the } \\
\text { structural capacity of an existing pavement. Also, } \\
\text { disturbance to traffic is limited and can be used for } \\
\text { busy highways. }\end{array}$ & $\begin{array}{l}\text { In most cases cold in-place recycled } \\
\text { materials require a curing period, } \\
\text { followed by an application of a wearing } \\
\text { course. Although smaller machines are } \\
\text { available, this technique can involve long } \\
\text { trains which may not be suitable for local } \\
\text { residential streets with very limited space } \\
\text { for maneuvering of equipment. }\end{array}$ \\
\hline $\begin{array}{l}\text { Full Depth Reclamation } \\
\text { (FDR) }\end{array}$ & $\begin{array}{l}\text { Can be used to treat rutting in layers below the } \\
\text { surface, including base; load associated, block and } \\
\text { thermal cracking; and maintenance patching. This } \\
\text { technique is particularly suitable for pavements with } \\
\text { base problems or insufficient structural capacity. } \\
\text { Since this is basically a cold in-place process, it has } \\
\text { all the advantages of cold in-place recycling, } \\
\text { including savings in transportation cost and energy } \\
\text { and no occurrence of air quality problems due to } \\
\text { emissions. }\end{array}$ & $\begin{array}{l}\text { Full depth reclamation usually results in a } \\
\text { new base, which must be covered with an } \\
\text { appropriate wearing course. As in cold in- } \\
\text { place recycling, a significant amount of } \\
\text { curing period may be required. Presently, } \\
\text { there is a lack of proper construction } \\
\text { guidelines and specifications for FDR, } \\
\text { and the whole process must be supervised } \\
\text { by an experienced person. }\end{array}$ \\
\hline
\end{tabular}

\subsection{Design}

\section{DESIGN OF RECYCLED MIXES}

The design process for any recycling technique whether; hot or cold mix recycling, has two main aspects:

- Mix design, specifying the types and quantities of RAP and virgin aggregates, virgin bitumen, cutback, emulsion and additive.

- Structural design defining the thickness of new layer as a function of traffic loading and pavement distress.

Several literatures have been reported suggesting various mix design methodology for different recycling techniques. A brief review of the mix design methods for various bituminous pavement recycling techniques suggested by various agencies are as under:

\subsection{Hot Mix Recycling}

The basis of mix design include the determination of material properties of RAP and new materials, evaluation and selection of an appropriate blend of RAP and virgin aggregate to meet gradation, selection of suitable grade of virgin bitumen binder to satisfy desired penetration and viscosity requirements, identifying need to add a recycling or rejuvenating agent to soften the existing aged binder, and selection of job mix formula that comply with stability, flow and air voids requirements.

ASTM D4887 [11] outlines the procedure for selection of quality of bitumen binder or recycling agent. This includes a viscosity blending chart enabling the designer to determine the percentage of recycling or rejuvenating agent to be added to the total binder to achieve desired value of absolute viscosity for the recycled bitumen mix. The Asphalt Institute suggests that when 20 percent or less RAP is used in a mix, no change in asphalt grade is required. However, for mixes with greater than 20 percent RAP, a drop in one grade is recommended to compensate for the greater viscosity of the oxidized binder[12]. According to NCAT, the fraction of RAP content in the total aggregate can be as high as 30 percent without impacting the properties of the new mix. Hussain et al. [13] have shown that RAP mixes designed using conventional Marshall mix design method performs either same or better than the conventional mixes, but when RAP percentage in recycled mixes is above 45 percent of the total mix, the flow properties decreases below required levels, indicating that the 
mixture is likely to be under stress during loading thereby, making them less resistant to cracking. However, Perez et al. [14] have shown through performance related laboratory tests that no relevant differences were observed between the mixes with " common" percentages of RAP and those with " high" percentages of RAP, and that the percentage of RAP in hot asphalt mixes can be increased without affecting the mix performance.Kandhal et al. [5] recommends selection of virgin bitumen binder one grade softer than the normal binder when RAP content is between 15 to 25 percent. However, for RAP content above 25 percent, use of AASHTO M323 testing procedure to select binder type is recommended.

The Asphalt Institute's manual on mix design methods for asphalt concrete[15] provides a method to determine necessary mix design characteristics such as stability, flow and air voids content for either Marshall or Hveen mix design methods. Mix design for hot-mix recycling includes the following steps:

- Obtain representative field samples of the reclaimed materials.

- Perform laboratory analysis to determine:

- Composition, properties of the reclaimed bitumen materials and its binder content

- Amount and gradation of new or recycled aggregate to be blended in the combined mix.

- The type and amount of bitumen modifier

- Select the optimum combination of mix components that meet the design criteria.

\subsection{Hot In-Place Recycling}

Itmay involve up to 100 percent recycling of the existing pavement unlike conventional recycled hot mix where the RAP is combined with a significant amount of new aggregate material. Thus, the condition and characteristics of the old mix has significant influence on the extent to which the existing pavement can be improved or modified. ARRA [3] identifies nine variables for HIR mix design as compared to five for a HMA mix design that HIR mix design.The variables for HIR mix design include:

- Recycling agent type

- Recycling agent source

- Recycling agent amount

- Virgin aggregate gradation

- Virgin aggregate amount

- Virgin aggregate source

- New asphalt binder type

- New asphalt binder source

- New asphalt binder amount

Although, several mix design procedures for HIR are available however, all the procedures are very similar. The following general steps are applicable whether traditional or Superpave. ARRA[3]modified by Button et al. [16]:

- Evaluation of existing HMA including RAP, new aggregates, and new bitumen binder selected.

- Determine gradation of RAP aggregate including bulk specific gravity, binder content in RAP and its properties to include penetration/ viscosity.

- Selecting the type and amount of recycling agent.

- Determining the requirement and amount of admix including aggregate gradation, its type, bulk specific gravity and absorption and amount and grade or preferred penetration/ viscosity of new bitumen binder.

- Preparing and testing both bitumen binder and mix specimens in the laboratory.

- Evaluating test results and determining the optimum combination of admix and recycling agent.

\subsection{Cold Mix Recycling}

The specifications and design of cold plant mix recycling of bituminous pavements are referred to in ASTM D4215[17]. Cold mix recycled mixes may be used for surface, base, or subbase courses. ARRA[18] guidelines recommends three different methods for cold mix bituminous mix design. These include; Marshal and Hveem methods intended for designing cold recycled mixtures with bitumen emulsion or emulsified recycling agents. Third method has been developed by Oregon State University for determination of required bitumen emulsion content.

Although there are no universally accepted mix design methods for cold mix recycling, the Asphalt Institute[19] recommends the following mix design process:

- Obtain representative field samples from the pavement or from the stockpiles [ASTM D979].

- Process samples and extract bitumen for use in mix design [ASTM D2172]. 
- Evaluate bitumen content, gradation of aggregate separated from the bitumen and recycled material [ASTM C136].

- Select amount and gradation of new aggregate to be added.

- Selection of bitumen binder or emulsion.

- Estimate bitumen demand of the combined aggregate.

- Estimate requirement of new bitumen binder in the mix based on the original aged bitumen in the RAP.

- Mix, compact and run test trial mixes.

- Establish job mix formula that meets optimum combination of mix components.

- Adjust job mix formula in field.

\subsection{Cold In-Place Recycling}

The Asphalt Institutehas recommended a modified Marshall mix type procedure for the design of CIPR mixes[20]. Mix design process for CIPR mixes have been recommended by Wirtgen Cold Recycling Technology Manual[21] and Caltrans[22] :

- Obtain RAP samples from the field using milling machine in order to get samples similar to during actual construction process.

- Determine RAP properties including; RAP gradation, moisture content, binder content, aggregate properties and properties of aged binder.

- Select the amount and type of new aggregate, if required.

- Select type and grade of recycling additive. The most common CIPR recycling additives are bitumen emulsions or emulsified recycling agents as they are liquid at ambient temperatures and are easily dispersed in the recycling mixture.

- Estimate the amount of recycling additive.

- Determine liquid content for coating. To provide adequate total liquid to coat the aggregate and aid in the compaction of final mixture, water is added to the CIPR mixtures. Optimum coating is determined by observing the minimum amount of added water that just costs the RAP and new aggregate, and when further addition of water does not improve this coating.

- Test trial mixtures for initial curing properties, final curing properties and moisture sensitivity.

- Establish job mix formula. The JMF includes the amount, grade and type of recycling additive, the minimum amount of water to be added and the amount and type of aggregate requirements.

- Field adjustments in the JMF may be required considering weather conditions, variation in the RAP or changed demand for recycling agent.

Murphy et al.[23] have shown that the addition of 20 to 25 percent of virgin aggregates in the CIPR process results in less voids and consequently, less flushing and improved stability. Castedo et al.[24] has shown that the amount of recycling agent has a significant influence on the behaviour of the mix, with the ideal range of recycling agent being between 2 and 3 percent by weight of dry RAP.

\subsection{Full Depth Reclamation}

Mix design process for FDR has been explained in the Wirtgen Cold Recycling Technology Manual[21] as:

- Obtain representative samples of RAP and underlying materials from field.

- Evaluate RAP for gradation, binder content, gradation of extracted aggregate, and aged binder.

- Determine gradation and physical properties of underlying granular layers.

- Select an amount and type of additional aggregate, if required.

- Estimate requirement of additional recycling, additive demand.

- Work-out requirement of pre-mix moisture content for coating.

- Testing of trial mixtures, initial curing properties, final curing properties, and moisture sensitivity.

- $\quad$ Establish job mix formula.

- Make adjustments according to field conditions.

\section{UNRESOLVED ISSUES}

While bituminous pavement recycling technologies are well established and widely in use for past 35 years, there is still considerable information void, particularly with regard to its rutting resistance, fatigue endurance, durability and material variability considerations related with the use of RAP. Detailed guidelines are desired for 
better laboratory prediction of filed performance by more correlation of field and laboratory measurements. Some issues that require emphasis include:

- Further information on the variability of RAP. The gradation of RAP is different from the gradation of original bituminous mixture, since it contains agglomerates rather than individual particles and has much reduced fine content.

- Validation of SUPERPAVE mix design procedures while designing mixtures containing RAP.

- Influence of fluctuations of RAP characteristics on the performance of new mixes.

- Performance of aged paving grade binder from RAP and its compatibility with polymer modified binders (PBM) on new mixes.

- An environmental code regarding gaseous emissions from hot mix plant recycling and HIPR.

- Influence of prevailing weather conditions while laying particularly on in-place recycling methods.

- Quality assurance and Quality control (QA/QC) is challenging.

\section{PAVEMENT RECYCLING IN INDIA}

While most of the developed nations have standardized the procedures and have made significant advancements in the bituminous pavement recycling techniques and in utilization of recycled materialsin pavement construction to reduce the carbon footprints and to promote sustainability in pavement construction, we in India are yet to make any significant advancement and here pavement recycling is still in nascent stage. Although, in India, more than 90 percent of the pavements are bituminous pavementsyet during their rehabilitation and maintenance, either the old pavement materials are being removed and dumped in a landfill or a new layer is paved on top of the existing pavement thereby, resulting in burial of the limited non-renewal resources.

India with its 33 lakh kilometers of road network is the second largest in the world. Nearly 60 percent of freight traffic and 88 percent passenger traffic is carried by the roads and annual growth is projected at 12-15 percent for passenger traffic and 15-18 percent for cargo traffic. The value of roadways and bridge infrastructure in India is expected to reach USD 10 billion by 2017. The length of National Highways is expected to grow from 92,850 kilometers in 2013-14 to 100,000 kilometers by the end of 2017. Government of India has also set an ambitious target of achieving 30 kilometer length of road construction per day. Apart from the investments in developing new roads, state transport agencies spend rupees worth thousands of crores annually to maintain and rehabilitate existing pavements. Nearly 15,000 tons of natural aggregates are required to build every one kilometer stretch of a highway in India. Pavement recycling is a logical and practical way to conserve our diminishing supply of construction materials and to reduce the cost preserving our existing pavement network. Recycling of pavements by re-using the existing materials will protect natural resources for future generation. Thus, the significance of adopting bituminous pavement recycling techniques for road construction in India cannot be overemphasized.

\section{VII.CONCLUSION}

The cost of construction using recycled mix are economical compared to virgin mix. Ability to mill and remove old, distressed pavement allows for more effective rehabilitation techniques. Severely cracked or rutted layers can be removed so that their damage is not reflected through a new surface layer.Multiple studies have shown that the structural performance of recycled mixes is equal and in some instances better than that of the conventional mixes. Recycling of pavements by re-using the existing materials will protect natural resources for future generation. Thus recycling is a sustainable pavement construction for the environment.

The use of recycled pavement construction is gaining popularity for its advantage over conventional materials including conservation of natural resources, conservation of energy, preservation of environment, reduced lifecycle costs, besides conservation of depleting oil-based hydrocarbon binders. Developed nations have already standardized the procedures to utilize recycled and secondary materials in the pavement construction. Thus, pavement recycling has become an attractive rehabilitation and maintenance alternative. Unfortunately, in India, the concept of bituminous pavement recycling has not yet gained much popularity. India has set ambitious road construction future targets which requires huge reserves of natural resources and oil-based hydrocarbon binders. It already has the second largest road network in the world, thus, it cannot afford to ignore bituminous pavement recycling anymore.

\section{REFERENCES}

[1]. J.A. Epps, D.N. Little, and R.J. Holmgreen, Guidelines for Recycling Pavement Materials, NCHRP Report No 224, Transportation Research Board, Washington, D.C., September 1980.

[2]. Pavement Recycling Guidelines, World Road Association (PIRAC), Cedex, 2003. 
[3]. Basic Asphalt Recycling Manual, Asphalt Recycling and Reclaiming Association, USA, 2001.

[4]. R. Karlsson, and U. Isacsson, Material-Related Aspects of Asphalt Recycling- State-of-the-art, Journal of Materials in Civil Engineering, Vol.18, Issue1, ASCE, Reston, pp81-92, 2006.

[5]. P. S.Kandhal, and R. B. Mallick, Pavement Recycling Guidelines for State and Local Governments,Federal Highway Administration, Publication No. FHWA-SA-98-042, December 1997.

[6]. Asphalt Cold-Mix Recycling, The Asphalt Institute Manual Series No20 (MS-20), Second Edition, 1986.

[7]. J. A. Epps, Cold Recycled Bituminous Concrete using Bituminous Materials, NCHRP, Synthesis of Highway Practice 160, Transportation Research Board, Washington, D.C., 1990.

[8]. J. A.Epps, R. L. Terrel, and D. N. Little, Recycling Pavement Materials and Urban Roads, May 1978.

[9]. R. B.Mallick, and A. Veeraragavan, Sustainable Pavements in India the Time to Start Is Now, NBMCW, September 2010.

[10]. An Overview of Recycling and Reclamation Methods for Asphalt Pavement Rehabilitation,Asphalt Recycling Association Manual, 1992.

[11]. ASTM D4887-93, Standard Test Method for Preparation of Viscosity Blends for Hot-Recycled Bituminous Materials, American Society for Testing and Materials, Annual Book of ASTM Standards, Volume 04.03, West Conshohocken, Pennsylvania.

[12]. Aspahlt Institute,Asphalt Hot-Mix Recycling, Manual Series No 20, Second Edition, Lexington, Kentucky, 1996.

[13]. A. Hussain, and Q. Yanjun, Evaluation of Asphalt Mixes Containing Reclaimed Asphalt Pavement for Wearing Courses,International Conference on Traffic and Transportation Engineering, 2012.

[14]. F. Perez, M. Rodriguez, J. DeVisscher, A. Vanelstraete, and L. De Bock, Design and Performance of Hot Mix Asphalts with High Percentages of Reclaimed Asphalt: Approach Followedin the PARAMIX Project, $3^{\text {rd }}$ Eurasphalt\&EurobitumeCongress, Vienna 2004- Paper 098.

[15]. Mix Design Methods for Asphalt Concrete and Other Hot-Mix Types,Asphalt Institute, Manual Series No.2, Lexington, Kentucky, 1993.

[16]. J. W. Button, D. N. Little, and C. K. Estakhri, Hot In-Place Recycling of Asphalt Concrete, Synthesis of Highway Practice 193, TRB, National Research Council, Washington. DC, 1994.

[17]. ASTM D 4215, Standard Specification for Cold-Mixed, Cold-Laid Bituminous Paving Mixtures, American Society for Testing and Materials, Annual Book of ASTM Standards, Volume 04.03, West Conshohocken, Pennsylvania.

[18]. Mixture and Structural Design of Cold Recycled Pavements, Asphalt Recycling and Reclaiming Association, Annapolis, MD, 1996.

[19]. Asphalt Institute, Asphalt Cold-Mix Recycling, Manual Series No 21, Lexington, Kentucky, February, 1983.

[20]. ASTM D1559-89, Standard Test Method for Resistance to Plastic Flow of Bituminous Mixtures Using Marshall Apparatus, American Society for Testing and Materials, Annual Book of ASTM Standards, Volume 04.03, West Conshocken, Pennsylvania.

[21]. Wirtgen Cold Recycling Technology", 2012 Edition, Wirtgen GmbH.

[22]. Caltrans, Flexible Pavement Preservation, MTAG Vol-I, Chap-13, In Place-Recycling, Second Edition, (Caltrans, February 2008).

[23]. D. T. Murphy, and J. J. Emery, Modified Cold In-Place Asphalt Recycling,Presented at the 1995 Annual Conference of the Transportation Association of Canada, Victoria, British Columbia.

[24]. Castedo, Humnerto, Significance of Various Factors in the Recycling of Asphalt Pavements on Secondary Roads,Transportation Research record No. 1115, Washington, DC, 1987. 